\title{
Synergistic, ecological education development: The Vietnam Consortium Fellowship Program ${ }^{1}$
}

\author{
Allan MacKinnon \\ Simon Fraser University, Canada \\ Le Van Hao \\ Nha Trang University, Vietnam \\ Nguyen Quoc Chinh \\ Vietnam National University, Vietnam
}

\begin{abstract}
This article presents an analysis of a learning community that formed in a project in science curriculum development at the tertiary level in Vietnam during the nineties. This 'Vietnamese Consortium Fellowship Program' was funded by the Canadian International Development Agency (CIDA) and delivered through Simon Fraser University (SFU) from 1993 to 1999. The aim of the project was to develop and implement a master of science (MSc) program in science curriculum research for twenty young professors of science selected from among the eleven universities of the consortium to assist in developing an educationally sound, up-to-date basic science curriculum for the initial phase of post-secondary science education in Vietnam.
\end{abstract}

\footnotetext{
${ }^{1}$ We gratefully acknowledge the financial support of the Canadian International Development Agency (CID A). An earlier version of this article was presented as a chapter in C. Linder, L. Östman, D. Roberts, P-O. Wickman, G. Erickson \& A. MacKinnon (Eds.) (2011), Exploring the landscape of scientific literacy (pp. 223-235), The Teaching and Learning in Science Series. Routledge: New York. It is reproduced and extended here with collaborating authors and permission from the Taylor and Francis Group LLC Books: License Number 3426130320173.
} 


\section{Introduction}

Following Soviet influence, the universities in Vietnam at the outset of Vietnam Consortium Fellowship Program were mono-disciplinary with few exceptions. During the project there was a merger of the main universities in Ha Noi and Ho Chi Minh City to form the (comprehensive) National University of Vietnam. This was accompanied by an effort to implement a transfer system modeled in part after the post-secondary education system in British Columbia. This meant making a dividing line between lower and senior level study, which the Ministry of Education and Training (MOET) did by introducing a two-phase system. In the first phase of study all students would take a general studies program for three semesters in a community college, likely but not necessarily in the countryside. The University of General Studies was formed at the outskirts of Ho Chi Minh City with modern residences for students. Having completed their general studies in the community colleges or the University of General Studies students would then transfer into the National University for specialization in the 'college' of Natural Sciences or the 'school' of Education, and so forth. This also entailed developing a credit system and a way of transcribing students' progress through their education.

Another dimension of the program had to do with the nature of science curriculum under development and how the fellows addressed issues of relevancy and student engagement. The program required fellows to examine the curriculum of their courses in terms of both the content of the subject matter involved as well as the intent, or purposes for learning the material. We explored various systematic purposes, or curriculum emphases (Roberts, 1982), that have appeared in science curriculum materials and text books over the past century. Some of the curriculum development that occurred in the project involved purposes of investigating the internal workings and logic of the scientific enterprise and would thus be consistent with Roberts (2011) Vision I for scientific literacy, while others would be considered examples of curricula that exemplify Vision II, that is the interactions of the scientific enterprise and scientific knowledge with societies and cultures. The latter seemed to be ripe for Vietnam in the postwar(s) era, given the social and environmental destruction that occurred over centuries of warfare. Theses titles that emanated from the project reflect this broad conceptualization of scientific literacy, but all of the innovations and research were done in situ with community engagement and participation at all levels. ${ }^{2}$

\footnotetext{
2 Thesis titles and authors include the following: Using case study and cooperative learning teaching approaches in a second-year physiology course at Dalat University—Doan Thi My; An environmental approach to the general chemistry curriculum for basic science students in Ho Chi Minh City University - Vo Thi Hong Tinh; An integration of bistory and demonstrations of physics into the introductory physics course - Le Van Hao; The social context of genetics education in Vietnam: A case study at Dalat UniversityNguyen Bich Lien; A case study of a computer-based laboratory course in calculus at Dalat University-Nguyen Huu Tan; $A$ teaching innovation to promote authentic science in a physics teaching laboratory in a Vietnamese university - Ho Huu Hau; The testing process in a Vietnamese university: An investigation of teachers' and students' perceptions-Nguyen Quoc Chinh; Effects of chemical demonstrations in teaching analytical chemistry_-Phan Thanh Chung; A combination of physics lectures and demonstrations using the learning cycle in physics teaching at the College of General Studies, Vietnam National University, Ho Chi Minh City_Tran Thi Thien Huong; A study of chemistry teaching with environmental issues at Nhatrang University of Fisheries-Phan Thi Nhi; Frequent classroom assessment and students' mathematics learning in a Vietnamese context_Le Thai Thanh; Teachers' and students' ideas about the use of multiple choice tests in physics: A study in a Vietnamese university-Duong Quang Minh; Students' approaches to learning physics in a Vietnamese university: An investigation of teachers' and students' perceptions - Nguyen Thi Ngoc Thuy; An investigation of the use of concept mapping in teaching and learning cellular respiration in a Vietnamese university — Vo Thi Thanh Phuong; $A$ case study of an...
} 
Reform of the post-secondary education system in Vietnam was fueled by a national 'Doi Moi,' or 'open door' transition from a centrally planned economy to a market oriented economy, which began in 1986. The early years of transition were characterized by a deterioration of the universities and by the early nineties national initiatives developed to restructure the education system. MOET seemed to recognize the need to establish policies of self-governance in the universities as part of the Doi Moi scheme, and we believe it was also recognized that the mono-disciplinary university was holding them back.

In the early nineties when this project began some of the science labs in the universities were poorly maintained and underutilized, if at all. In many cases there was some equipment in the science faculties but it wasn't being used because the teachers were untrained in its use or in any kind of pedagogy that would involve using the equipment. To put the teachers' meager skills in context at the time of this project, it is helpful to note that the teachers' salaries were only about fifty US dollars each month, which was nowhere near enough to support a family. The teachers were often preoccupied with second and even third jobs making it more difficult for them to learn new teaching or laboratory techniques. The majority of teachers in Vietnamese universities in the early nineties had domestic bachelor degrees in their disciplines but had not yet pursued graduate study. They had been the bright students in their own undergraduate programs and had been selected by the universities to remain after graduation as teachers.

To add to the complexity of carrying out this project in a meaningful way, the senior administration changed hands in all of the consortium universities during the life of the project with new rectors and vice-rectors being appointed every five years. The success of the project required briefing every newly appointed rector and vice-rectors. Similarly, the senior administration at SFU changed through three presidents during the project and newly appointed senior administrators had to be briefed about the nature of the work we were doing in Vietnam; delegations were going back and forth across the Pacific and so there were times when SFU hosted visitors from the consortium universities and MOET. The succession of university administrations could have been an impediment to the project but because of the measures taken to compensate for this it may have contributed to the success of the project in the end. Whatever we did to sustain the continuity of the program administratively and position the SFU fellows within their institutions seemed to decrease the risk of diluting the project in the din of changing administration.

....innovation in chemistry teaching at the College of General Studies, Vietnam National University — Ho Chi Minh City—Luu Thu Nghi; Self-regulated learning in a Vietnamese context_Ta Thi Han Hoan; The use of Donald Schön's conceptualization of reflection-inaction in Vietnamese teacher education-Nguyen Thanh Thuy; $A$ case study of cooperative learning in inorganic chemistry tutorials at the Vietnam National University, Ho Chi Minh City_Le Thi So Nhu; Factors affecting choice of major in science in the University of Natural Sciences in Ho Chi Minh City, Vietnam-Huynh Huu Tri; Applying problem-solving approaches in a general physics laboratory in the College of Natural Sciences, Ho Chi Minh City, Vietnam_Lam Quang Vinh. 


\section{Program Design and Selection of Fellows}

The purpose of the Vietnam Consortium Fellowship Program was to assist a consortium of universities increase its members' human resource and institutional capacities for basic science programming. It was understood in Vietnam as in most developing regions that improving basic science education was required in order to strengthen the applied science disciplines upon which effective regional development depends. The MSc program in science education included upgrading in the basic science disciplines (physics, chemistry, biology, mathematics) and practical experience in SFU's Faculty of Science as well as instruction in basic science curriculum design, pedagogy and educational research in the Faculty of Education. Participatory and applied action research was fundamental to the program as the fellows undertook thesis research activities relative to their instructional and curriculum responsibilities in their Vietnamese institutions. The students developed a curriculum project within their home institutions, collected data for a period of six months on average and then returned to Canada to write and defend their theses. The MSc program spanned three years. All of the empirical research took place in Vietnam, while all of the courses for the program together with thesis preparation and defense took place in Canada.

Twenty Vietnamese fellows came to Canada in four successively staggered cohorts of five members each. The first group graduated in 1996, the fourth group in 1999. In total eleven women and nine men were selected for the program. Five fellows were selected from Can Tho University; four from the University of Da Lat, two from the Nha Trang University of Fisheries, one from the Ha Noi Agricultural University, and eight from various universities affiliated with the Vietnam National University in Ho Chi Minh City, including four from the University of Natural Sciences, two from the University of Agriculture and Forestry, one from the University of Education and one from the Pedagogical University of Technology.

The fellowships were also distributed among the disciplines of science. The twenty fellowships included three in biology, eight in chemistry, six in physics, and three in mathematics. There was a further attempt to balance the disciplines as the fellowships were allocated within the consortium universities.

The candidate selection and the distribution of the scholarships have been reviewed here in considerable detail as these merit some analysis in regard to our general understanding of learning in practice (Schön, 1983; 1987) and curriculum deliberation (Schwab, 1969). In terms of process all interviews and decisions took place in the context of SFU admissions practices but in full consultation with partner universities. Universities were asked to put forward candidates. The SFU team interviewed these candidates, often with a senior administrator of the partner university present and selected the fellows on the basis of their ability in English, their competency as scientists, their apparent commitment to the university and the idea of the project, as well as the way they were being positioned in their universities by their administrators. We thought about the candidates in terms of their individual merit, but also about how they would interact as a group, what they would bring to the team and how they were connected to the existing administration. We discussed these sorts of things in terms of 
both the academic program and the socialization that we felt would occur within the program. In terms of the sustainability of an educational innovation or a learning community the selection of the participants is one of the most important considerations of all - what must be ensured is the equal representation of the stakeholders or partners in the decisions surrounding the selection of the participants and the distribution of the scholarships. The selection of candidates will pave the way to the future interactions among them. At least some of this can be anticipated and foreshadowed by a careful consideration of each candidate in terms of the idealized whole.

\section{Results}

The fellows engaged in their coursework enthusiastically, interacting with professors and fellow graduate students alike. A wide variety of graduate courses in education were encountered including courses in the history, philosophy, psychology and sociology of education, science education, models of teaching, educational research, science curriculum design and implementation. In addition, two field courses were developed specifically for this program-one in the faculty of science and one in the faculty of education. The field course in the faculty of science provided an introduction to the organization of curriculum and instruction in lecture and laboratory courses in the basic sciences. The field course in the faculty of education included observations and analyses of curriculum and instruction in the basic sciences in high schools and university colleges in British Columbia. In some cases, field excursions were arranged to suit the interests of the fellows. For example, one of the physicists visited Lethbridge Community College in Alberta for two weeks to observe a self-paced electronicsteaching laboratory. Fellows were given access to undergraduate courses in their respective disciplines at their discretion so they could observe or even audit the same courses that they would teach in Vietnam. Thesis committee members and examiners were selected from the faculties of education and science as appropriate to the topics selected. Some of the thesis work required use of the science labs at SFU and in these cases laboratory instructors at SFU often became involved with the Vietnamese fellows' work. For example, one of the theses investigated practical activities in polymer chemistry for the candidate's organic chemistry course back in Vietnam. This student worked in one of the SFU chemistry labs for several weeks learning various techniques for practical work in this field.

There was a distinctive solidarity and strength that developed among the fellows. Each individual had a unique role within the cohort and the group at large. There was a leader appointed informally but recognized by everyone as the leader in each cohort. Leaders would organize activities, speak on behalf of the cohorts at various functions, make sure everyone had a role and pitched into whatever activity was at hand. The leaders would collect opinion and provide advice on behalf of the group. The leader of the first cohort was considered to be the leader of the entire group of twenty fellows. The leaders of each of the four cohorts still act as leaders today whenever there is any activity involving the SFU fellows as a group. The older women provided moral guidance to the group. They could indicate their approval or dismay in subtle ways that would ripple through the group and remind me that this was indeed a different culture with distinctive traditions. 
The strength of the project consisted in the interlocking design of the twenty fellows' programs to yield theses comprising a first and second year basic science curriculum for consortium universities and associated colleges. A further strength was the development of a cadre of trained faculty members to teach that curriculum and to develop further reform and innovations in science curriculum, and courses in education and educational research in Vietnamese faculties of education. Some of the fellows felt resistance to their ideas among a few of their teaching colleagues. Their experience showed that the degree of local receptivity varied among the consortium universities and their colleagues. Without exception, however, resistance to the new approaches proposed by the fellows was never perceived from the university administrations. This experience was widely discussed in forums involving all of the fellows, SFU faculty advisors, and other project participants. As a result the fellows of cohorts two, three and four made a greater effort to ensure their theses included coverage of issues raised by colleagues at their home institutions. For example testing was a matter of great concern in at least one university, therefore some of the theses dealt directly with issues surrounding measurement and assessment.

Another issue that became evident following the return of cohort one fellows to Vietnam was in how they were 'placed,' in either science or education departments at their home universities. In some cases, fellows were permitted a choice; in others they were assigned to particular departments on their return, not always to their liking. Fellows working in education departments felt they had a greater opportunity to use their expertise in education. However, they feared losing touch with their scientific disciplines and regretted the loss of the better-equipped labs that were now present in the science faculties. Fellows trained in education but working in science departments had greater difficulty using their newly acquired skills in the field of education and found that colleagues did not recognize their credentials because their degrees were not in the basic sciences. Further, the comparative rigor of the SFU program was not always recognized since a master's degree in a Vietnamese institution typically spans a single academic year rather than three. The initial difficulties became less prominent in time and many of the fellows are now thriving personally and professionally.

All twenty fellows completed their MSc degree successfully. At Can Tho University two fellows were appointed to the education faculty upon their return to Vietnam. Another became chair of his chemistry department almost immediately after he returned. Two became involved in new initiatives that built upon their thesis work (one project concerned the use of demonstrations in chemistry lectures, the other models of 'reflective practice' in problem solving in physics laboratories). Two of the five fellows from Can Tho went on to complete their PhDs in education, one in the United States and the other in the Netherlands. The fellow who went on to study in the United States continued to explore measurement and evaluation in tertiary education. The fellow who studied in the Netherlands continued her work with Donald Schön's ideas in mathematics teacher education.

In the Vietnam National University in Ho Chi Minh City one of the fellows whose thesis dealt with testing practices in Vietnamese universities was appointed to the testing division to assist in designing professional development for university teachers in 
writing tests, interpreting results and systematically improving tests over time. He and another fellow developed and hosted a national television program similar to the Canadian program, Reach for the Top, based on competitions among high school students in knowledge and applications of chemistry. Another two fellows were assigned to work on innovations in the chemistry and physics teaching laboratories at the College of General Studies and the College of Natural Sciences of the Vietnam National University in Ho Chi Minh City. One of these fellows went on to serve two terms as dean of education at the University of Agriculture and Forestry, which became a comprehensive university during this period called Nong Lam University. At the Pedagogical University of Technology one of the fellows of the third cohort studied the use of frequent testing in mathematics and subsequently led a review of testing in his department. Of the eight fellows in Ho Chi Minh City two have gone on to doctoral study, one in chemistry (England) and the other in physics (France).

In Da Lat three fellows became involved in new course development (one of these courses is in educational research). One secured a research grant to develop environmental education materials for high school teachers and used these materials in a science teaching methods course with rural high school teachers from the Da Lat region. Another became the chair of the computing science department. One of the fellows from Da Lat University married a Japanese professor and eventually moved to Japan where she currently works as a peace educator on cruise ships.

In Nha Trang one fellow became the chair of the physics and mathematics department of the Nha Trang University of Fisheries and later the director of the educational quality assurance and testing division of the comprehensive Nha Trang University when it was formed. He participated in numerous research projects and published fairly prolifically after his return to Vietnam. He eventually completed his PhD in Australia. The other fellow at Nha Trang University secured a research grant through MOET to develop 'science, technology and society' teaching materials for high school chemistry teachers. The fellow in Ha Noi became the dean of educational psychology at the Ha Noi University of Agriculture. She also taught occasionally in Ho Chi Minh City on special assignments with some of the other fellows. The fellows were brought together to design and teach courses in educational research for the University of Social Sciences and Humanities in Ho Chi Minh City, even though none of the fellows were selected from this institution.

A December 1997 assessment revealed Vietnam's relationships with CIDA and SFU to be highly appreciated and respected at the local level as evident in the examples above. Their administrators perceived the SFU fellows as a vital resource for future developments in science education and teacher education within Vietnamese universities and public schools. University administrators recognized aspects of the fellows' expertise to include updated knowledge of their respective science disciplines; knowledge of educational thought, practice and research; experience in educational action research based in their own teaching practice; leadership skills and commitment to contribute to further educational development in Vietnam; proficiency in spoken and written English; and knowledge of and experience in Canadian culture and education. Most of the twenty fellows were assigned to administrative positions where they were fairly well positioned to enact some of their new ideas about science curriculum. One of 
the fellows eventually left his university and took a job with a business firm. As mentioned above, another left Vietnam and is currently living in Japan. Of the remaining eighteen five have gone on to PhD study in Australia, England, France, the Netherlands and the United States. Various fellows worked together as a team on several research and development projects after returning to Vietnam. The fact that they were spread among several universities turned out to be an asset as it allowed for collaborations among the universities on various projects, which brought higher profile to their initiatives. Most of the fellows still communicate with one another and with me fairly regularly.

A major factor contributing to the program's success was the cohesiveness and camaraderie of the fellows. Without the group's consistent efforts to assist each other academically and with adjustment problems their accomplishments would have been nearly impossible for many of them individually. While the efforts were spontaneous, they were reinforced by discussion around thesis proposal preparation emphasizing fellows' contributions to an informal collective. When cohort two arrived it was incorporated into this existing ethos. Cohorts three and four also integrated well with the earlier cohorts, though there were apparent generation differences between the younger members of cohorts three and four and the first and second cohorts. Although the members of cohorts three and four were young and arguably less experienced than the members of the first two cohorts, they sustained the tradition of mutual support and assistance established by the first cohort. A substantial time investment by concerned professors and advisors was essential to the program's achievements as was the special status accorded to the project by the university administration.

The SFU fellows had strengths as individual scholars and teachers but they were also seen collectively as a 'critical mass' for future developments in Vietnamese universities and public schools. Since they were spread throughout the country, however, one of the immediate challenges to sustainable development that was recognized by the university administrators lay in making visible the initiatives and accomplishments of the fellows. But rapid and extensive restructuring of universities and government in Vietnam led to uncertainty about how the fellows might fit into the larger picture of reform in higher education. There was a need for a broader dialogue between the fellows and appropriate constituencies about the direction and nature of further reform in higher education. It was in this area where we focused our thinking about sustainability. Discussions were held in March 1994 and again in February 1996 with Dr. Tran Phuoc Duong regarding long-term planning for fellows reintegrating after program completion and for coordination of fellows' contributions to consortium universities' curriculum development efforts. During the latter visit we visited the College of General Studies, which was established to teach a common basic science curriculum to all freshman students. Since that time, however, the two-phase system of higher education in Vietnam was reconsidered and terminated partly due to a change of personnel in the MOET and partly due to difficulties encountered implementing the credit system. The College of General Studies was closed in January 1999 and those fellows who had been placed in that institution were reassigned to the College of Natural Sciences of the Vietnam National University in Ho Chi Minh City. 
There was a need for the fellows together with their administrators and colleagues to discuss their ideas with ministry officials who were determining directions and policies for educational reform in Vietnam. Specifically, there was a need to discuss how the fellows' expertise and interests might best serve and be supported by the national initiatives at the time. With such rapid development and change in Vietnam during those years - in government and universities alike-the need to enable dialogue and develop shared understandings among educational constituencies was particularly important. Although the expertise and interests of the fellows seemed to fit the goals of reform in a general way (i.e., increased 'active learning' of students, enhanced relevance and applicability of curriculum, science-society-environment themes, promising new teaching approaches), there was a need to establish a specific work plan that recognized the potential of the fellows to contribute to future reform and development in education. In light of these assumptions many of the ideas discussed during the planning missions pertained to strategies for sustaining and promoting the network of SFU fellows in Vietnam. One of the ideas that was shared and strongly supported at each of the institutions was to bring all twenty fellows together at the completion of the program to present and discuss their work in a 'science education meeting.'

This science education meeting was designed to enhance the impact of the CIDA Vietnam Consortium Fellowship Program and to promote continuous and sustainable educational development in Vietnam beyond the completion of the project. We reasoned that this broad goal could be precipitated by (1) disseminating the fellows' achievements within their institutions and MOET and (2) by sustaining the consortium universities' and the fellows' dialogue with Canadian science educators in a manner that would support their internal reform efforts and bridge to future projects and developments.

CIDA gave us permission to hold a science education meeting in Vietnam to bring together the twenty fellows to showcase their work to teaching colleagues, university administrators, MOET officials, the Canadian Ambassador to Vietnam with representatives from the Canadian Embassy and potential funding agencies including the Vietnam representatives from the Asian Development Bank and the World Bank. We were required to apply to the People's Committee together with the rector of the National University of Vietnam in Ho Chi Minh City to gain permission to hold the meeting.

The meeting was a great success with over one hundred people attending in the end including all those mentioned above, senior administrators from all of the consortium universities, the vice-president research and dean of graduate studies from SFU, the Canadian Ambassador to Vietnam and the entire staff of MOET's divisions of higher education and international relations. There were also television news teams from local and national stations and the meeting received a great deal of attention in the media. Other government officials and representatives from the People's Committee including the president of the People's Committee in the Khanh Hoa province were present to contribute their part to the proceedings with opening and closing ceremonies and other related activities and formalities that accompanied the conference. 
The proceedings of the meeting were available at the outset of the conference, which was particularly impressive given that many of the papers were presented in both English and Vietnamese. The first few days of the meeting were devoted to the SFU fellows and the research they had done. Each student presented his or her thesis. The language of presentation was English but translation to Vietnamese was provided (the SFU fellows served as one another's translators). These presentations were interspersed with commentary and speeches given by the government officials. After all of the theses were presented there were responses from MOET, the university administrators and the Canadian science educators. At the end of the conference the director of the higher education division of MOET told the fellows they could change the curriculum at their discretion-they needn't ask for permission.

\section{Insights}

Any approach to community development ought to consider the educational fabric of the developing community. Schwab (1969, 1971, 1973, 1983) provides a practical approach to curriculum and curriculum deliberation among stakeholders in the community broadly. His attention to the common places provides a comprehensive outline of the dynamics at hand in this program. For example, the concluding conference showcasing the fellows' research can be thought of as a deliberative inquiry among stakeholders. It is useful to think of a community along these lines as a network of evolving competencies and understandings, in which people are engaged with one another along what might be thought of as a continuum or gradient of knowledge, understanding and ability. Following this view one might understand foreign participation in community building in terms of stimulating the development and exchange of knowledge, understanding and ability at the local level. A beginning premise of this project was that educational programs within and among institutions could be designed to link together in ways that enhance the development and exchange of knowledge and understanding in the community at large. Another premise was that the linking of programs and development initiatives would help to strengthen relations among educational institutions in Vietnam thereby deepening and sustaining dialogue and analysis about teaching and learning in Vietnamese higher education. To fully grasp this notion of 'linking' we need to think of individuals working together in a concerted and productive way. In order to reform any curriculum one would need to build this sort of infrastructure and we can see in the Vietnam Consortium Fellowship Program how, on a small scale, the design of the program provided the outline for this infrastructure, namely the successive cohort model that was used to create opportunity for collaboration and mentorship within the community.

Metaphors drawn from the biological sciences are useful for understanding a learning community particularly in terms of a dynamic living system. The metaphor of a seed for example can offer systemic, dynamic analyses of projects and programs. The Vietnam Consortium Fellowship Program was like a seed in that it grew under the proper conditions and became an inter-related part of the community over time. This was discussed by the fellows many times-about how they might think of themselves as a 'seed' that we were about to plant in Vietnam, a seed that we would need to care for and 
nourish in order for it to take a life of its own. This notion of seed became an interesting acronym for us, as we think of the project in terms of it being synergistic ecological education development. A learning community has a synergy - a life of its own so to speak - which allows it to flower and bear fruit, albeit often in unanticipated ways. This kind of unpredictability is a good thing because it brings about robust interconnections in the community and ensures that various people are developing initiative and taking ownership in creative ways. A good example was the national television program based on a high school competition in chemistry, which never could have been predicted to come from a program such as ours. Synergy seems to us to carry with it synchronicity, serendipity and spirituality, which allow people to bring their beliefs and their determination to bear upon their collective efforts. The fellows had an amazing sense of loyalty and altruism toward their country, a strong sense that their collective efforts would benefit their society.

The concept ecological gives rise to systemic ideas of inter-relatedness. Teaching and learning relations are typically thought of in terms of one person in transition-the learner: the learner is in transition from a state of not knowing to a state of knowing. The teacher allows the transition to occur, but does not undergo any kind of change. But if one thinks in ecological terms then the teacher, the learner and knowledge itself are in a process of formation because teaching, learning and understanding are all transactional events. There is something to be taken from each exchange by all partners-nothing is wasted. This kind of thinking allowed us to see the project participants as a community of learners-our students, our partners and ourselves-in a rich web of interconnections as an interwoven fabric of developing understandings and competencies growing together, learning with and from one another. This theoretical infrastructure in turn provided the foundation for implementing our ideas and innovations in science curriculum.

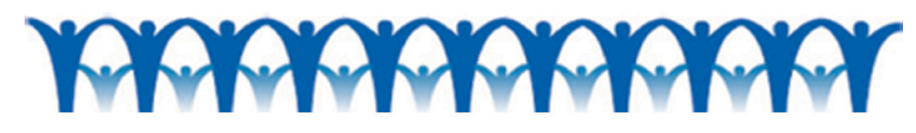

Figure 1: Representation of a learning community

The image presented in Figure 1 captures some of our theorizing about learning communities, which has been shaped by our experiences in our work together in Vietnam. It is a pattern taken from the balcony of a youth center in Can Tho. This was the pattern in the hand railing around the balcony - that of a chain or circle of paper dolls alternating large and small in a form that represents a flower blossom. The significance of the flower blossom is not only to represent the collective as a living system but to remind us that the seed is within each individual blossom, each person. This image captures the idea of mutual support for growth vis-à-vis preparing for the next generation, representing some of the ecological insights that could serve as metaphors for understanding the dynamics of learning communities, and it was used for a time at SFU as a logo in the 'Field Programs' area, which was involved with in-service teacher education through graduate diploma programs focused on educational practice. The time the fellows spent in Canada was like a pupa stage for them. Upon reflection we believe that the success of the program was due in part to the intensity of the situation 
the fellows experienced during their study in Canada. They were in residence together, apart from their families and their heavy teaching assignments. They were in a foreign country studying in an additional language in the field of education, which was a new area of study for them. They had to support each other and part of this intensity had to do with the fellows being on 'time out,' that is, having time away from their normal teaching duties for contemplation, review and refocusing. Some of this notion of intensity had to do with the fact that the fellows would eventually be reintroduced into the teaching force in Vietnam; this was an opportunity for a fresh start especially after this period of contemplation, of transformation. So if we could conceptualize a pupa stage for a collective then I think we would have the outline of a learning community. Members of a learning community are in a process of transition but the group as a whole is also is constantly evolving.

'Khong sao dau' translated into English means as a close approximation, 'no problem.' But it means more than just, 'no problem,' as English speakers would use the expression. English speakers would say, 'no problem' to indicate that they don't mind doing something or that it would be little effort or inconvenience to do it, or that they weren't offended by some action. In the Vietnamese language, 'khong sao dau' means that everything will turn out okay on its own, or if you leave it alone it will be all right, almost as though there is a destiny inherent in things themselves. A Vietnamese person would say, 'khong sao dau' to mean, 'don't worry; things will work out on their own' almost as if to say, 'it's not in your hands, relax.' In a way this expression epitomized the Vietnamese fellows and the learning community created about them. The idea of 'khong sao dau,' fits well with ecological thinking - the notion that nothing is wasted, that everything is on its way to becoming something else and ultimately will be recycled in the ecosystem. There is synergy, synchronicity, serendipity and spirituality inherent in shared commitments and beliefs, common goals, mutual respect and joint ownership, all of which develop as learning communities mature. We include a short selection form the first author's reflections:

What all of this came to mean for me as the coordinator of the project was that I needed to simply let it all unfold before me, to give a little push or a pull here and there as things progressed, but to mainly focus my energy and attention on supporting rather than controlling, on nurturing rather than judging. As the group unfolded, the members of this learning community set their own individual courses or pathways within the common purpose set by the program. My main role was to help each student develop a sense of intellectual independence and agency in the right way, at the right time, in the right place. I was simultaneously tilling the soil in Vietnam to prepare for the 'seed' we would be planting as a group. This involved frequent visits to the senior administrators in each institution to provide updates and raise issues about sustaining the efforts of the SFU fellows upon their return to Vietnam. My concern was doing all of this in a way that highlighted the twenty individuals with their special qualities and talents. 


\section{References}

Roberts, D. (1982). Developing the concept of 'curriculum emphases' in science education. Science Education, 66(2), 243 - 260.

Roberts, D. (2011). Competing visions of scientific literacy: The influence of a science curriculum policy image. In C. Linder, L. Östman, D. Roberts, P-O. Wickman, G. Erickson \& A. MacKinnon (Eds.), Exploring the landscape of scientific literacy, (pp. 223-235). The Teaching and Learning in Science Series. Routledge: New York.

Schön, D. (1983). The reflective practitioner: How professionals think in action. New York: Basic Books.

Schön, D. (1987). Educating the reflective practitioner: Toward a redesign in the schools of the professions. San Francisco: Jossey-Bass.

Schwab, J. (1969). The practical: A language for curriculum. The School Review, 78(1), 1-23.

Schwab, J. (1971). The practical: Arts of the eclectic. The School Review, 79(4), $493-$ 542.

Schwab, J. (1973). The practical 3: Translation to curriculum. The School Review, 81(4), $501-522$.

Schwab, J. (1983). The practical 4: Something for curriculum professors to do. Curriculum Inquiry, 13(3), 239 - 265. 